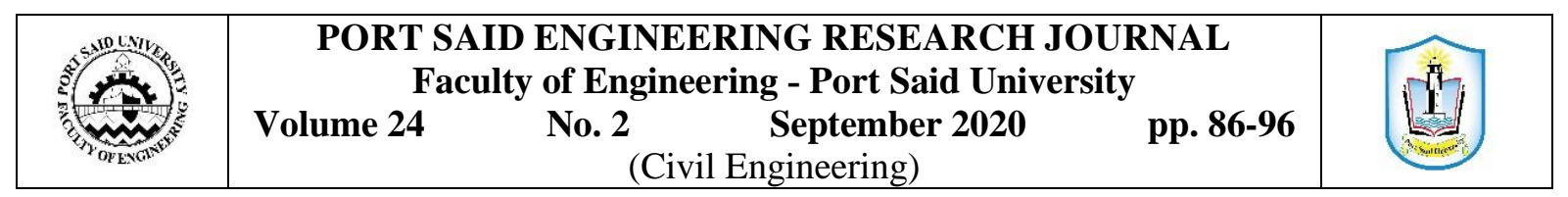

\title{
Parametric Study on Steel Girders with Corrugated Webs
}

\author{
Muhammad Shukry', Tarek Sharaf ${ }^{2}$, Ashraf Elsabbagh ${ }^{3}$, Mohamed ELGhandour $^{4}$
}

Received: 3 October 2019; Accepted: 18 April 2020

\begin{abstract}
I-shaped Steel Girders with Corrugated Webs [SGCW] are used in steel structures because of their notable advantages. SGCW permits using a thin web plate without using stiffeners. This girder is useful for eliminating the use of stiffeners and larger thicknesses that contribute to the reduction in the weight and the cost of the girder. In this paper, a numerical study based on the Finite Element Analysis [FEA] was conducted to predict the behavior of SGCW. The verification study was conducted for previous experimental tests. Based on the previous investigations, the parametric study was carried on to investigate the actual behavior of SGCW with different parameters such as the web thickness, the girder height, the web shapes, and the corrugated angles under different loads. The results of the parametric study showed the effect of each parameter on the overall load carrying capacity of the beams and indicated that the corrugated angle is the most effective parameter for SGCW.
\end{abstract}

KEYWORDS: Steel Girder with Corrugated Webs, Finite Element Method, Web Thickness, Corrugation Angle.

\section{INTRODUCTION}

Corrugated girders were used in the steel structures buildings because they have several advantages. Corrugated girders can carry high loads due to its corrugated web and permits using the thin web without stiffeners that leads to reduce the weight of the girders so reduce the cost of the program [1] to create and analyze the studied models.

In general, studies on the behavior of SGCW were carried out by experimental, finite element and theoretical analysis methods. The Experimental studies were conducted by Heungbae et al. [2], by creating nine specimens of corrugated girders in order to study shear buckling strength of SGCW. Prabha [3], studied the behavior of cold formed steel with trapezoidal corrugation in web by varying the aspect ratio and angle of corrugation. From the experimental results it is observed that as the angle of corrugation increases, the load carrying capacity increases fabrication. The literature review illustrated that the strength of the web girders with different shapes of corrugations is better than the girder of the flat

${ }^{I}$ Senior Engineer, Zagazig University Consulting Office, corresponding author,email: mo_elmahdy@hotmail.com

${ }^{2}$ Associate Professor, Faculty of Engineering, Civil Engineering Department, Port Said University, email: tarek.sharaf@eng.psu.edu.eg

${ }^{3}$ Associate Professor, Faculty of Engineering, Civil Engineering Department, Port Said University, email: Ashraf_ims@yahoo.com

${ }^{4}$ Professor of Steel Structure, Faculty of Engineering, Civil Engineering Department, Port Said University, email: dr.elghandor@gmail.com

DOI: 10.21608/pserj.2020.17735.1010 web. The Finite Element Method [FEM] was used in this research by ANSYS® software

Elgaaly and Seshadri [4], performed five experimental tests on simply supported girders with different position of the load. In all cases, the failure was due to bending of the flange with twisting and crippling of the web under the test load. Kovesdi et al. [5], determined the patch loading resistance of corrugated web girders of a real bridge by tests. Wang [6], tested eleven specimens for corrugated girders to study the behavior of the SGCW under static loading.

Abdel-Khalek et al. [7], studied the shear behavior of three cantilever girders with corrugated. Qi Cao et al. [8], studied shear behavior of corrugated steel webs in $\mathrm{H}$ shape bridge girders. Chan et al. [9], investigated the bending behavior of steel structural girder with corrugated web subjected to three-point loading. Divahar and Joanna [10], presented the results of the experimental study on load carrying capacity of cold formed SGCW. Denan et al. [11], carried out an experimental study on the lateral torsional buckling behavior of steel girder with trapezoid web. Arunkumar et al. [12] and Krishnan et al. [13], investigated cold formed steel girder with corrugation in web with varying depth. The Finite Element Analysis [FEA] investigations were performed by Elgaaly and Seshadri [4]. Based on their previous research experiments, a FEM was developed to analyze the patch loading failure. Luo and Edlund [14], conducted finite 
element study using the ABAQUS $®$ program. Based on the FEA results, it was found that the increase of the angle of corrugation changed the buckling mode from global buckling to local buckling. After one year, Luo and Edlund [15], studied the ultimate strength of SGCW under patch loading using FEA method. The studied factors were the loading position, load distribution length and several geometric parameters. Based on the numerical results obtained, an empirical formula for the prediction of the ultimate strength is suggested. Limaye and Alandkar [16], determined the buckling strength of the girder with corrugated web. Zhiquan and Wenlong [17] studied the influence of the corrugation angle and the profile dimensions on corrugated steel webs. Aggarwal et al. [18], study the local shear buckling behavior of SGCW using the program ABAQUS.

Finally, based on the previous experimental and FEA investigations researches, the theoretical method was developed. Elgaaly and Seshadri [4], carried out the numerical analysis and the experimental work on SGCW and based on their numerical analysis and the experimental work, a formula was developed. Duong et al. [19] presents the results of analytical study of the lateral torsional buckling of an I-girder with trapezoidal web corrugations under uniform moment. The results were compared with previous studies of researchers such as Lindner [20] and Jiho Moon et al. [21].

The objective of this research is to study the behavior of girders with corrugated webs subjected to various types of loads using the FEM. Based on the validated results, a parametric study is conducted for 207 [3D] finite element models by changing the geometric parameters such as the web thickness, the girder height, the web shapes, and the angles of corrugation under different loads to determine the effective parameters and better understanding of the behavior of corrugated web girders.

\section{FINITE ELEMENT MODELING}

\subsection{Verifications Study}

The verification study was carried out using FEM by ANSYS $®$ program [1] for two different experimental tests for corrugated girders. One of these tests was subjected to patch load tested by Kovesdi et al. [5], while the second test was loaded statically by Wang [6]. The comparison between both the experimental and the FEM results is considered the basis for checking the validity of using the FEM in the parametric study.

\subsubsection{Patch Loading Resistance of Girders with Corrugated Webs}

The aim of the verification for this research is to determine the behavior of FEA model that was conducted by ANSYS ${ }^{\circledR}$ program [1] for SGCW subjected to patch loading and compared its results with experimental tests that were conducted by Kovesdi et al. [5].

\subsubsection{Description of the Models}

Figure 1 shows the geometry of the corrugation profile that was used by Kovesdi et al. [5]. The bearing stiffeners were placed at the end of the girders from the same girder steel plate with $20 \mathrm{~mm}$ thickness. The corrugation profile is the same for all specimens and the angle of corrugation is $39^{\circ}$ for all specimens. All models behavior was defined as linear elastic hardening plastic using multilinear isotropic hardening. The yield and ultimate strengths of the flange and the web as shown in Table 1 as well as Young's modulus, E and Poisson's ratio, $v$. The material is supposed to behave linear elastic until reaching the yield strength by Young's modulus, after that the material is assumed to follow linear hardening with a reduced hardening modulus $\mathrm{E}_{\mathrm{r}}$ equals to $0.01 \cdot \mathrm{E}=2100 \mathrm{MPa}$.

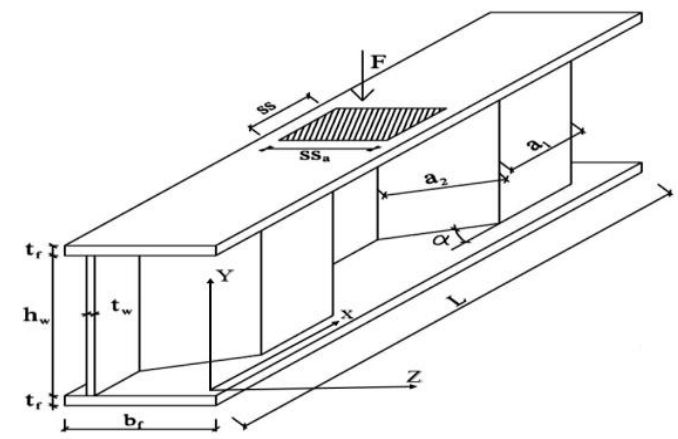

Figure 1: The geometry of corrugated girders from Kovesdi et al. [5].

Table 1: The material properties for flange and web girder [5].

\begin{tabular}{|c|c|c|c|c|}
\hline Element & $\begin{array}{c}\text { Yield } \\
\text { strength } \\
\text { Fy (MPa) }\end{array}$ & $\begin{array}{c}\text { Ultimate } \\
\text { strength } \\
\text { Fu (MPa) }\end{array}$ & $\begin{array}{c}\text { Elastic } \\
\text { modulus } \\
\text { E (MPa) }\end{array}$ & $\begin{array}{c}\text { Poisson's } \\
\text { ratio (v) }\end{array}$ \\
\hline Flange & 379 & 517 & 210000 & 0.3 \\
\hline Web & 373 & 542 & 210000 & 0.3 \\
\hline
\end{tabular}

2.1.1.2. Finite Element Analysis

The FEA models were created to simulate the behavior of corrugated web subjected to patch loading tested by Kovesdi et al. [5]. The applied load effect as a patch load on upper flange of the studied girder as shown in Figure $r$. Figure 2 shows the applied boundary condition was created at each end the girder, one end was restrained only in $\mathrm{X}$ and $\mathrm{Y}$ direction, allowing the movement in the $\mathrm{Z}$ direction, while the other end of the girder was restrained in the three direction of $X, Y$ and $Z$. The stage of the element meshing is very important for the FEA, as the accuracy of the results depends on it. The mesh sensitivity analysis study was performed to study the effect of density on the accuracy of the numerical analysis results. Based on these results the appropriate mesh was chosen in the FEA. This study were conducted to provide the accurate results with less run time. Three models of steel corrugated web were created to show the three different element mesh sizes, namely, coarse, intermediate and fine mesh. 


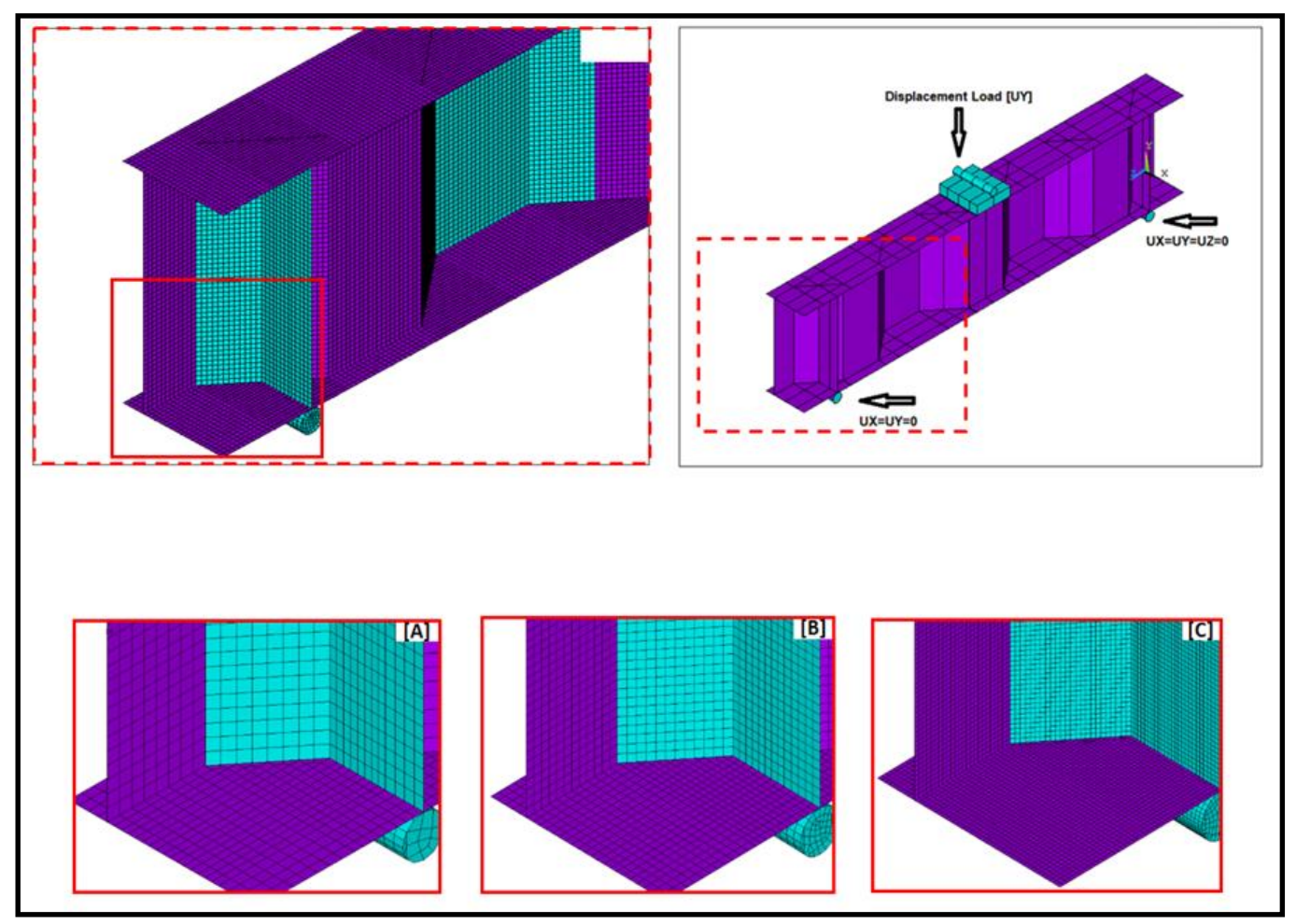

Figure 2: The mesh sensitivity [A] coarse mesh, $[\mathrm{B}]$ intermediate mesh, and [C] fine mesh and boundary conditions of typical corrugated girder.

The total element number was about 21000 elements for the coarse mesh, 37000 elements for the intermediate mesh, and for the fine mesh the total number was about 155000 elements, as in Figure $r$ [A, B and C], respectively.

According to the sensitive mesh study, Figure 3 shows the effect of using different mesh sizes on the load displacement response for the studied corrugated web. The comparison results of the FE models with fine mesh produced the most accurate results, but may take longer run time. While, the FE models with coarse mesh leads to less accurate results, but smaller run time. Based on the previous results, the intermediate size mesh is the appropriate size for the FEA which produced acceptable accurate results with acceptable computing run time.

\subsubsection{Result and Discussion}

\subsection{Load Displacement Relationship}

During the tests, the applied force and displacements were measured on different positions, where Transducer 1 was placed on the web in $50 \mathrm{~mm}$ distance from the upper flange, Kovesdi et al. [5]. This transducer measured the horizontal displacement of the loaded fold and Transducer 2 measured the vertical displacement of the tested girder at the mid span under the lower [unloaded] flange. Figures 3 shows the comparison of the numerical analysis and experimental for specimen 1.

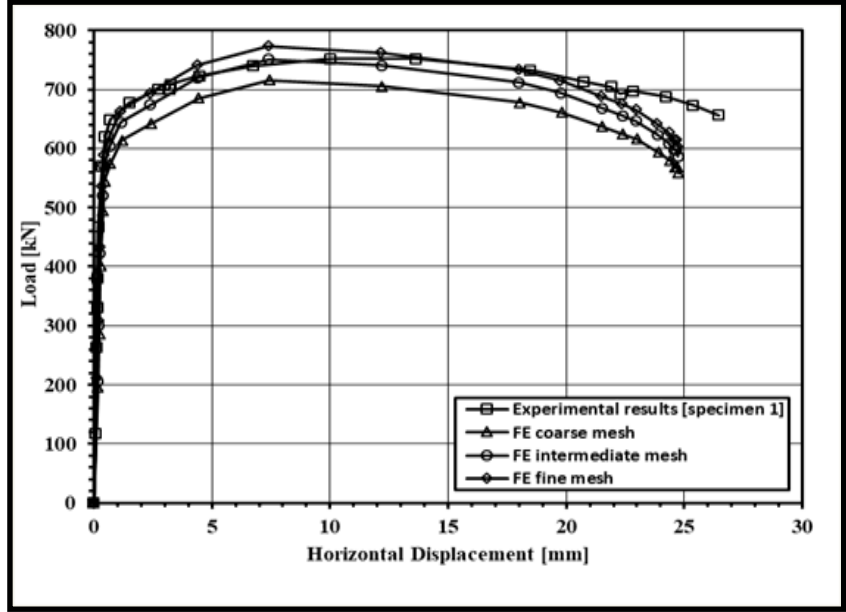

Figure 3a: Comparison of load-displacement (horizontal) curves for specimen 1 Kovesdi et al. [5] 


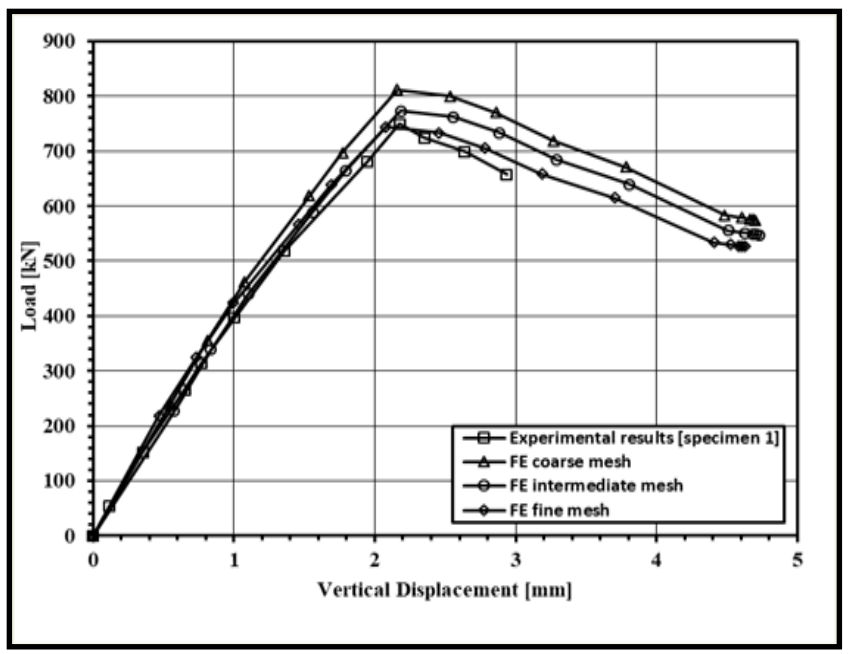

Figure 3b: Comparison of load-displacement (vertical) curves for specimen 1 Kovesdi et al. [5]

\subsection{Failure Modes}

Figures 4 shows the comparison of the numerical and experimental failure modes for two specimens. On the right side of the figures the experimental failure modes and on the left side the result of the finite element results are presented. The comparison is made for all test specimens and presented here for two girders. It proves that the structural behavior of the tested girders and the numerical models show good agreement.
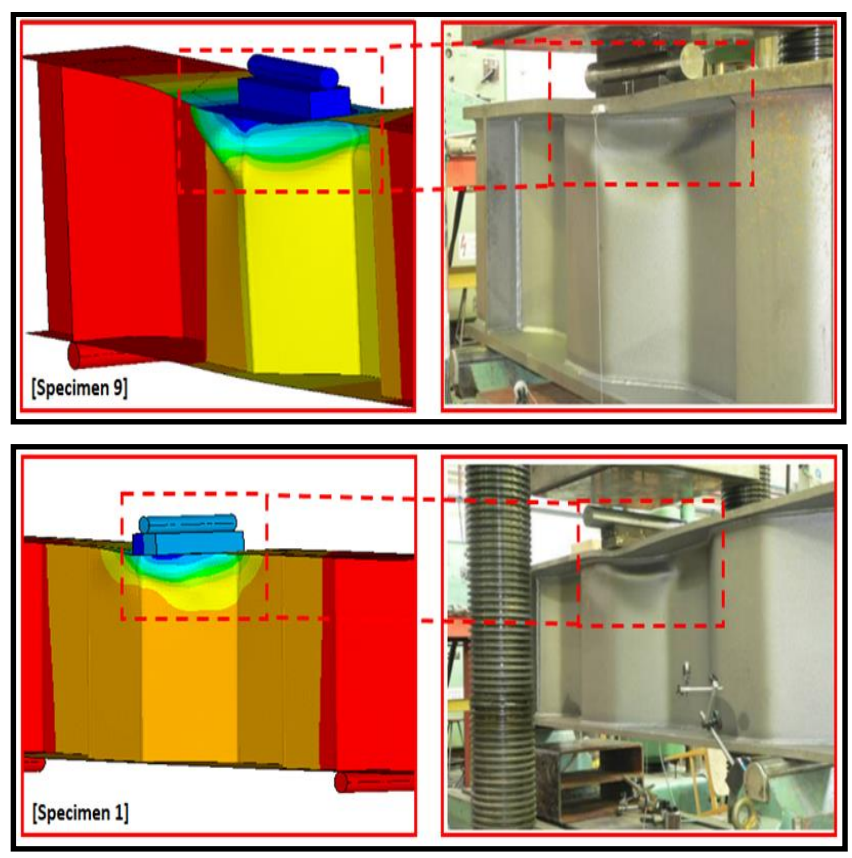

Figure 4: Comparison of ultimate failure modes for Specimens 1 and 9.

\subsubsection{Behavior of Steel Girders with Corrugated Webs and Tubular Flange}

The aim of the verification for this research is to determine the behavior of FEA that was conducted by ANSYS ${ }^{\circledR}$ program [1] for SGCW under static loading and compared its results with experimental tests that were conducted by Wang [6].

\subsubsection{Description of the Models}

Wang [6], designed eleven specimens with different parameters to analyze the behavior of steel girder. These specimens was categorized to three groups of SGCW. The first group consisted of two specimens [S1 and S2] subjected to shear load while the second group studied the LTB for three specimens [At5c3, At8c3 and At8c4]. The third group studied the actual behavior of the bending for six specimens from Bd1 to Bd6. Three stiffeners were used in all the studied girders that were located at the supports and under the location of the load. The purpose of using these stiffeners was to transfer the loads to web and prevent the local crippling of the tubular flange. The material properties for all the studied groups of steel girders were modeled as elasticplastic material behavior with kinematic hardening.

\subsubsection{Finite Element Analysis}

FEM were developed for the tested girders using nonlinear analysis using ANSYS program. From the previous sensitive mesh study in the patch loading validations, to obtain accurate results from the mesh, the intermediate mesh size was recommended. Figure ${ }^{\circ}$ shows the applied boundary conditions at which the supports were modeled as simple support. The load was applied along a transverse line of the upper surface of the compression flange above the mid stiffener, as shown in Figure ${ }^{\circ}$.

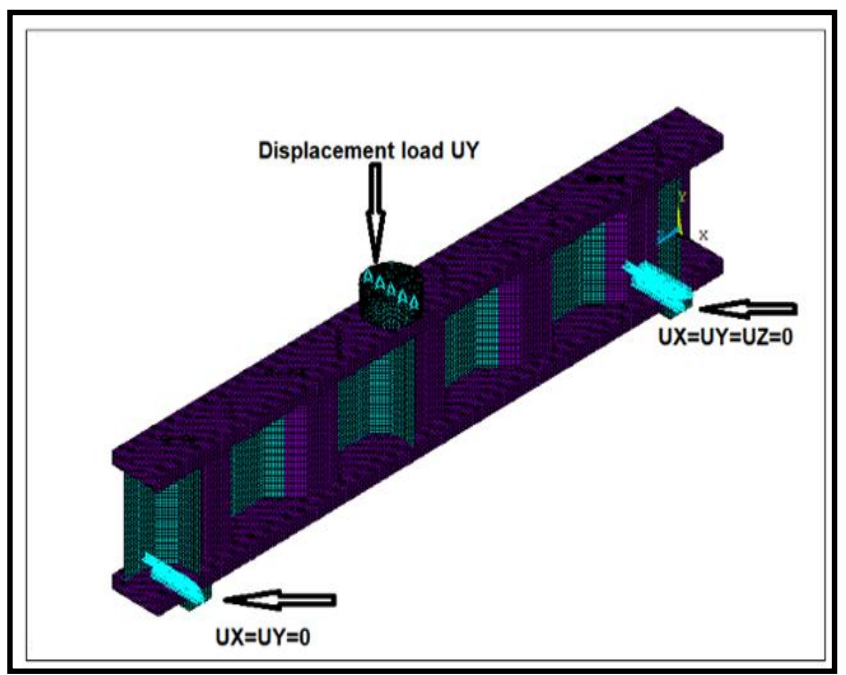

Figure 5: Finite element mesh and boundary condition of typical corrugated girder.

\subsubsection{Results and Discussion}

\subsection{Load Displacement Relationship}

Based on the deformed shape of the steel girder, the vertical displacement for the girder can be determined. From 
Figure 6, when comparing the results of the load displacement curves for the FEA with the experimental results, it can be noted that the initial range of loading for all girders is linear and the agreement between the FEA and the experimental results is very close. While for the nonlinear range loading, there is a small difference between the FEA and the experimental results, because in the FEA the stress strain relationship for steel sections was defined as elastic perfectly plastic which means the strain hardening was neglected. Also, based on the sensitive mesh study, the intermediate size mesh is the optimal element size for the FEA which produced accurate results with acceptable run time.
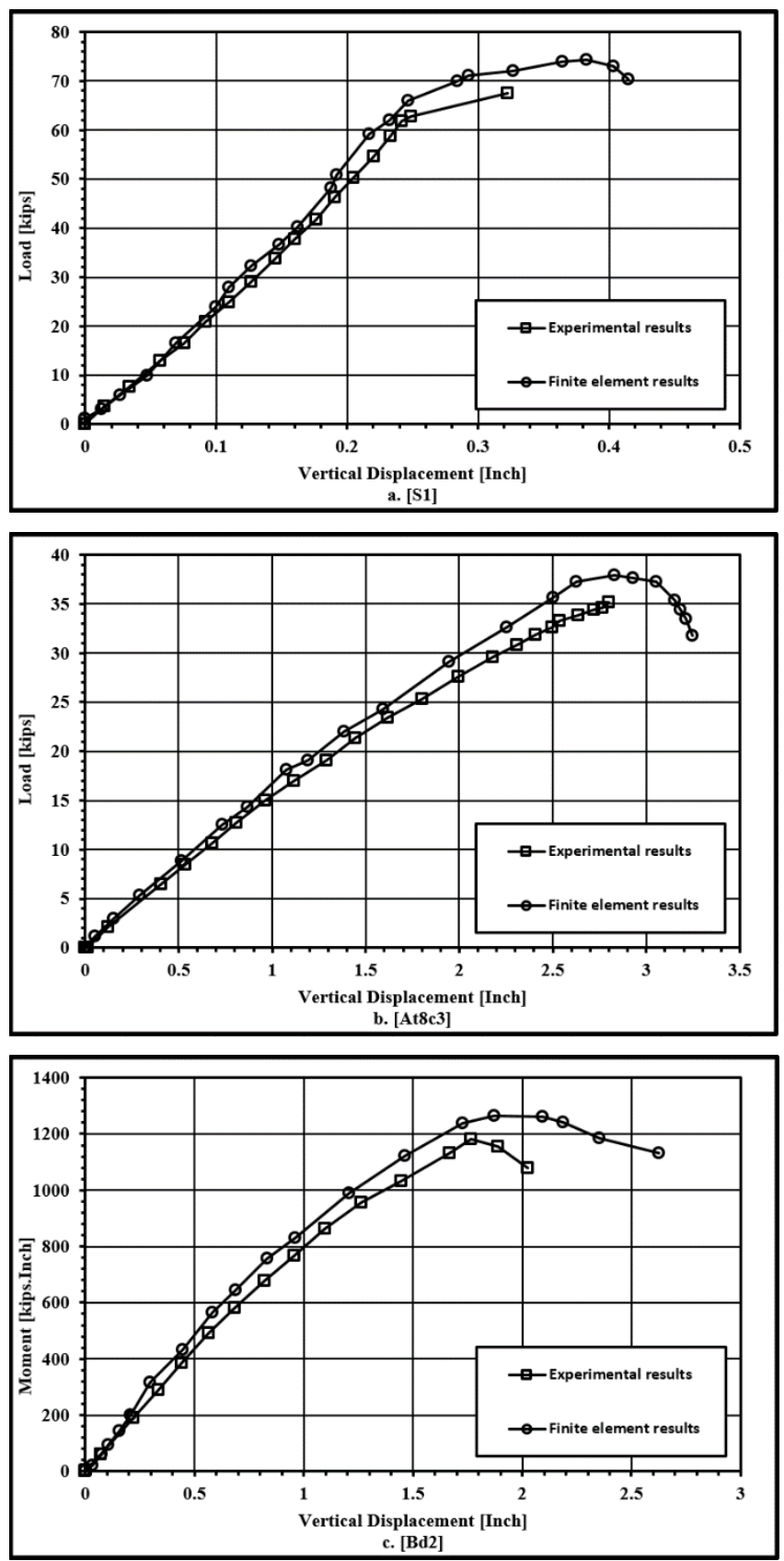

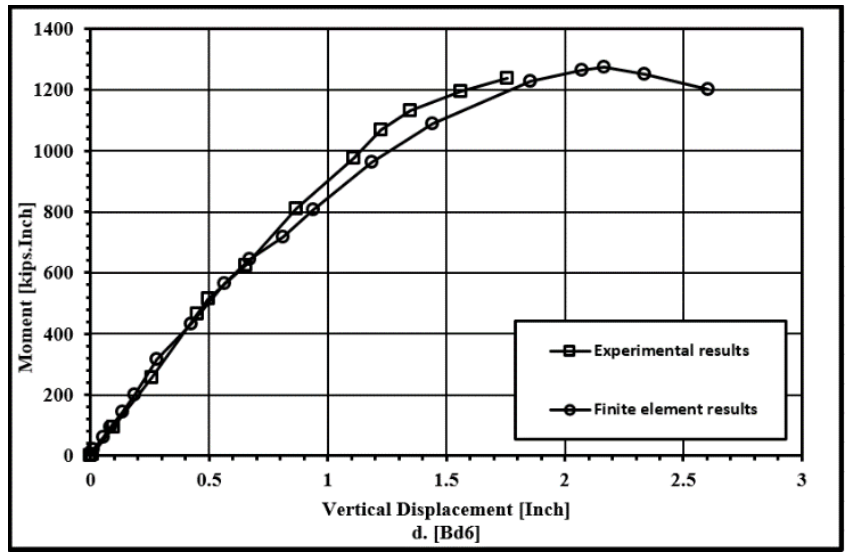

Figure 6: Experimental and numerical load displacement curves

\subsection{Failure Modes}

Failure mode for specimen [S1] show the buckling behavior of girder under the effect of shear. Shear buckling mode of the girder is local buckling in the web, while the effect of tubular flanges can be ignored in analyzing due to the shear stress in tubular flanges is very small compared that in the web. In specimen Bd2, buckling mode of the upper flange is local buckling near the center of the girder as shown in Figure 7.
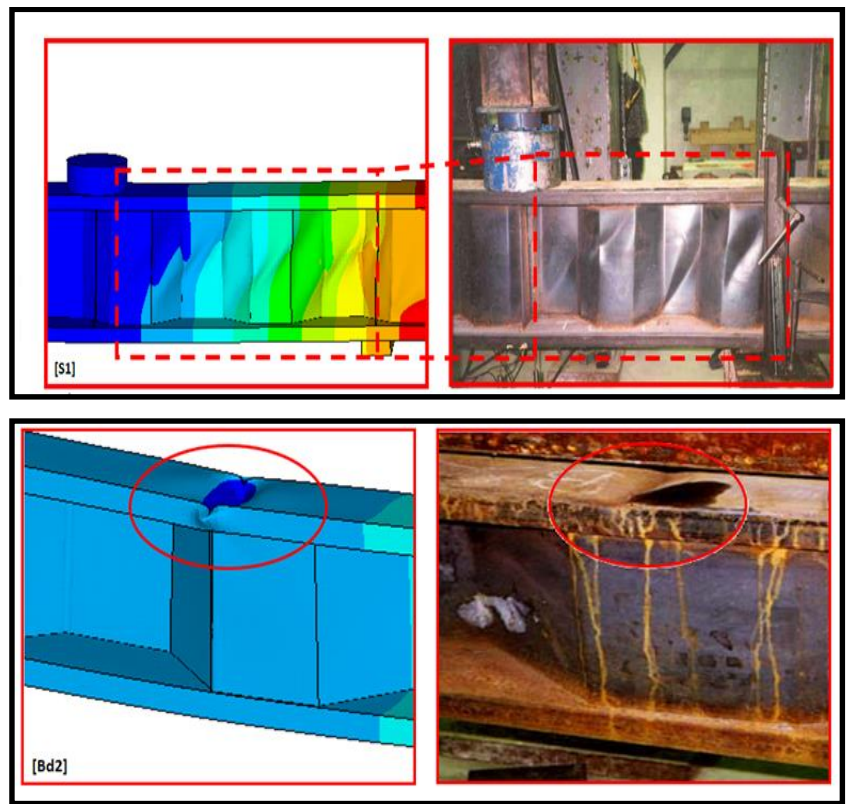

Figure 7: Experimental and numerical failure modes for specimens. 
Table 2: Parameters of the studied specimens.

\begin{tabular}{|c|c|c|c|c|}
\hline $\begin{array}{c}\text { Corrugation } \\
\text { angle }[\alpha]\end{array}$ & $\begin{array}{c}\text { Web } \\
\text { Height }[\mathbf{h w}] \\
\text { mm }\end{array}$ & $\begin{array}{c}\text { Web } \\
\text { Thickness }[\text { tw }] \\
\text { mm }\end{array}$ & $\begin{array}{c}\text { Flat } \\
\text { panel width } \\
{[\text { b] mm }}\end{array}$ & $\begin{array}{c}\text { Corrugation } \\
\text { depth } \\
{[\mathrm{hr}] \mathrm{mm}}\end{array}$ \\
\hline $0^{\circ}$ & \multirow[t]{2}{*}{400} & \multirow[t]{2}{*}{1.5} & \multirow[t]{2}{*}{0} & \multirow{3}{*}{50} \\
\hline $25^{\circ}$ & & & & \\
\hline $45^{\circ}$ & \multirow[t]{2}{*}{600} & \multirow[t]{2}{*}{3} & \multirow[t]{2}{*}{50} & \\
\hline $65^{\circ}$ & & & & \multirow{2}{*}{100} \\
\hline $90^{\circ}$ & 800 & 4.5 & 100 & \\
\hline
\end{tabular}

\section{PARAMETRIC STUDY}

Based on the verification study, a parametric study was conducted to develop a 3D FEM corrugated girder to study the effect of the different parameters. The aim of this study is to predict a better behavior of corrugated girder under different loads, determine the influence of the effective parameters on load and displacement capacity and understand the girder response and provide useful data for design of steel corrugated girder.

\subsection{Model Description}

A total of 207 full 3D FE models were created to study the behavior of steel corrugated girders under the effect of different loads. All the girders were arranged according to certain labels as shown in Figure 8. The girders consisted of the flange, web, and stiffener where the dimensions of the flange and the stiffener are constant [width $200 \mathrm{~mm}$, thickness $10 \mathrm{~mm}$ ]. The length of girder, $4000 \mathrm{~mm}$, while the other parameters are shown in Table $r$ and Figure 8.

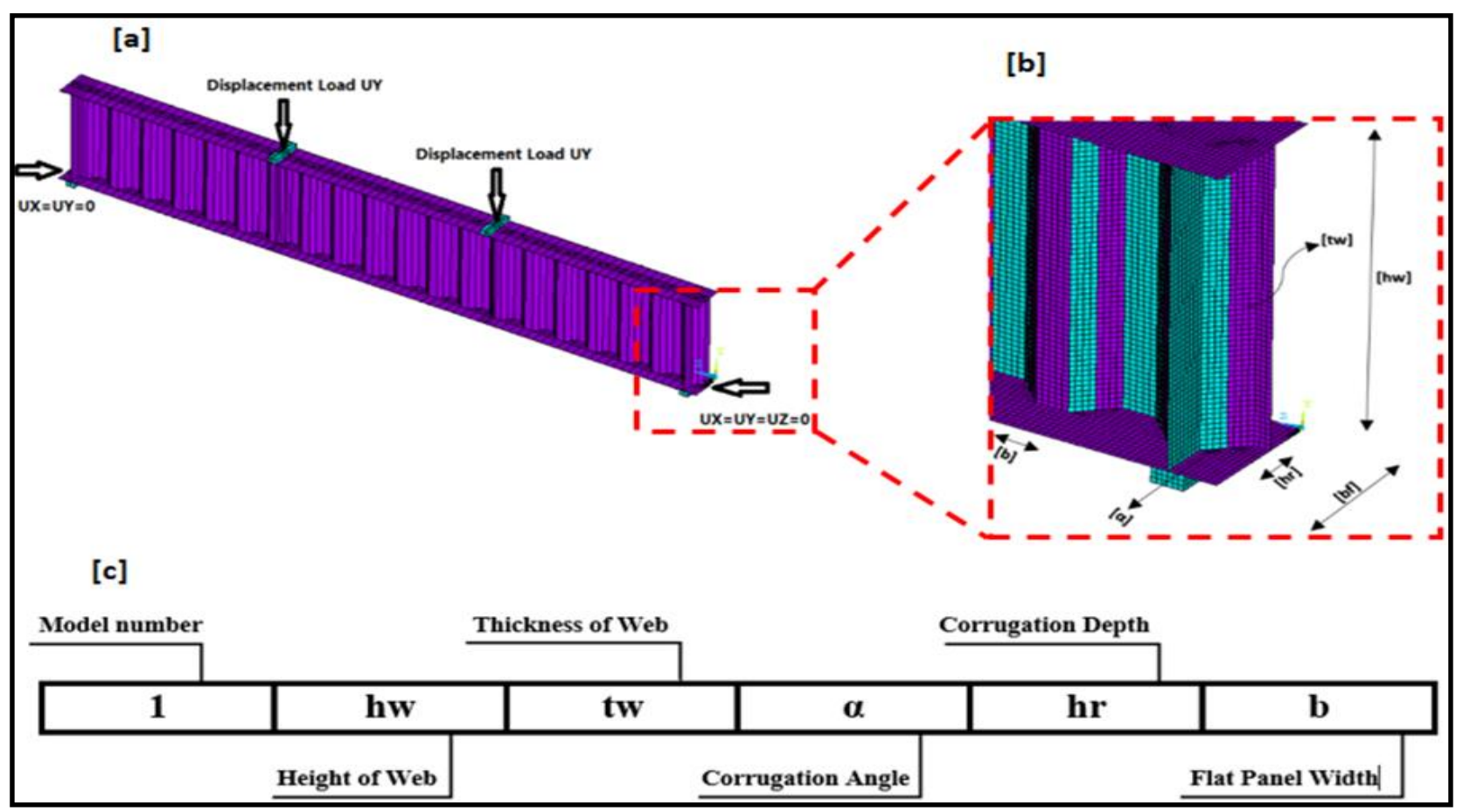

Figure 8: Typical 3D finite element model of the corrugated girder [a,b] and Finite element model label [c]. 


\subsubsection{Material Properties}

The material properties for all parts of steel girders were modeled as elastic-plastic material behavior with kinematic hardening, based on the test of Kovesdi et al. [5]. The Young's modulus is assumed to be $210000 \mathrm{MPa}$ for all parts while the yield and the ultimate stress are equal to $376 \mathrm{MPa}$, $460 \mathrm{MPa}$, respectively, and Poisson's ratio is 0.3 . The properties of these material remain constant throughout the analysis process.

\subsubsection{Boundary Conditions and Loading System}

To obtain an accurate solution, a boundary condition was created at each end of the girder. One end was restrained only in $\mathrm{X}$ and $\mathrm{Y}$ directions, while allowing the movement in the $\mathrm{Z}$ direction and the other end of the girder was restrained in the three directions of X, Y, and Z. A displacement $\mathrm{Uy}=200$ $\mathrm{mm}$ is applied statically under two point concentrated loading at $1 / 3$ span of the girder at the upper flange, as shown in Figure 8.

\subsection{FEA and Discussion of Results}

A parametric study was performed on 207 SGCW of IPE 400, 600 and 800 profile steel sections with different configurations. The studied parameters were girder height of web, thickness of web, corrugation angle, corrugation depth and flat panel width. The girder displacements were measured at the center of the lower flange.

\subsubsection{The Load-Displacement Relationship and Failure Modes}

The load-displacement relationship shows the behavior of SGCW subjected to various types of loads. All measured load-deflection curves are investigated and compared to each other. The analysis showed that most of the differences occur in the post-ultimate behavior. Some specimens in the current study as shown in Figures 9-12 and while reading the results it is observed that:-

Figure 9 compares between the flat web and corrugated web with angle $45^{\circ}$, while other dimensions remain constant. In case of flat web, the ultimate load is lower than the case of corrugated web, whereas in case of flat web linear part of the curve ended at load $52.15 \mathrm{kN}$ which means the first yielding in the web or in the flange depending on the flange and web geometries. Between load $47.05 \mathrm{kN}$ and $66.09 \mathrm{kN}$ the flange and web plates are yielding at the same time and the ultimate load is reached at load $66.09 \mathrm{kN}$, while in case the corrugated web with angle $45^{\circ}$, Linear part of the curve ended at load $157.57 \mathrm{kN}$ and the ultimate load is reached at load $170.34 \mathrm{kN}$.

Figure 10 compares between the corrugated depth $50 \mathrm{~mm}$ and $100 \mathrm{~mm}$, while other dimensions remain constant. In case the corrugated depth $100 \mathrm{~mm}$, ultimate load is lower than the case of the corrugated depth $50 \mathrm{~mm}$, whereas in case the corrugated depth $100 \mathrm{~mm}$ linear part of the curve ended at load $79.89 \mathrm{kN}$ and the ultimate load is reached at load 110.92 $\mathrm{kN}$, while in case the corrugated depth $50 \mathrm{~mm}$ linear part of the curve ended at load $99.27 \mathrm{kN}$ and the ultimate load is reached at load $121.29 \mathrm{kN}$.

Figure 11 compares between the web height 400 and 800 $\mathrm{mm}$, while other dimensions remain constant. In case the web height $\leqslant 00 \mathrm{~mm}$, ultimate load is lower than the case of the web height $\wedge .0 \mathrm{~mm}$, whereas in case the web height $\leqslant 00$ $\mathrm{mm}$ linear part of the curve ended at load $138.11 \mathrm{kN}$ and the ultimate load is reached at load $161.28 \mathrm{kN}$, while in case the web height $1.0 \mathrm{~mm}$ linear part of the curve ended at load $328.08 \mathrm{kN}$ and the ultimate load is reached at load 375.11 $\mathrm{kN}$.

Figure 12 compares between the web thickness 1.5 and 4.5 $\mathrm{mm}$, while other dimensions remain constant. In case the web thickness $1.5 \mathrm{~mm}$, ultimate load is lower than the case of the web thickness $4.5 \mathrm{~mm}$, whereas in case the web thickness $1.5 \mathrm{~mm}$ linear part of the curve ended at load 99.27 $\mathrm{kN}$ and the ultimate load is reached at load $121.29 \mathrm{kN}$, while in case the web thickness $4.5 \mathrm{~mm}$ linear part of the curve ended at load $158.83 \mathrm{kN}$ and the ultimate load is reached at load $183.28 \mathrm{kN}$.

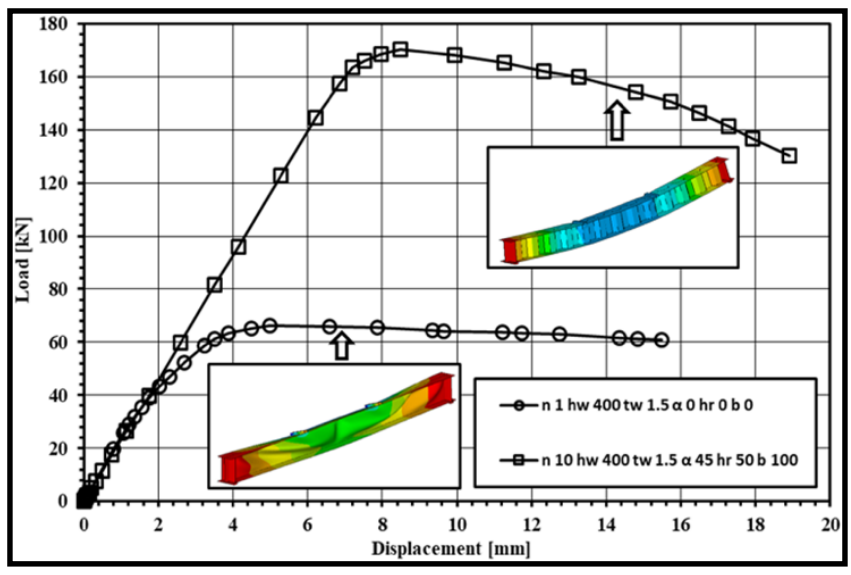

Figure 9: Comparison between the flat web and corrugated web for model number 1 and 10, respectively

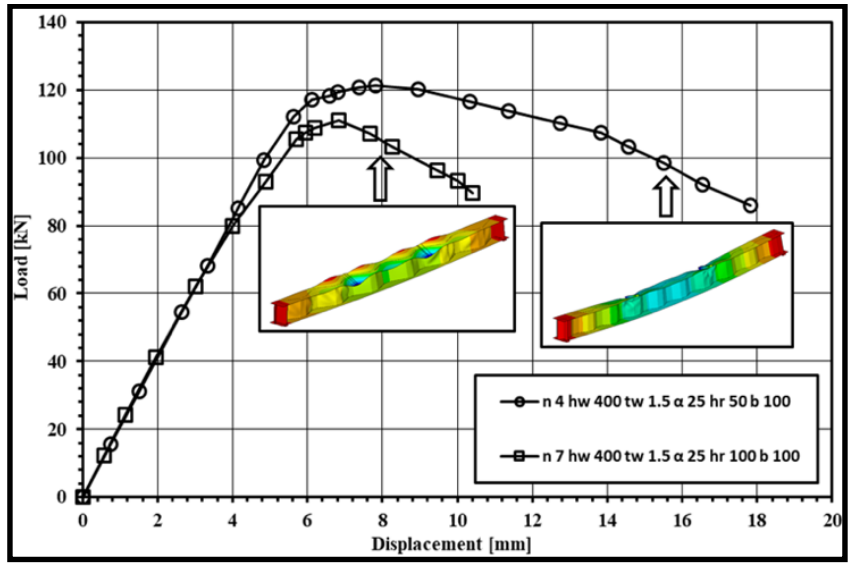

Figure 10: Comparison between the corrugation depth 50 and $100 \mathrm{~mm}$ for model number 4 and 7 , respectively 


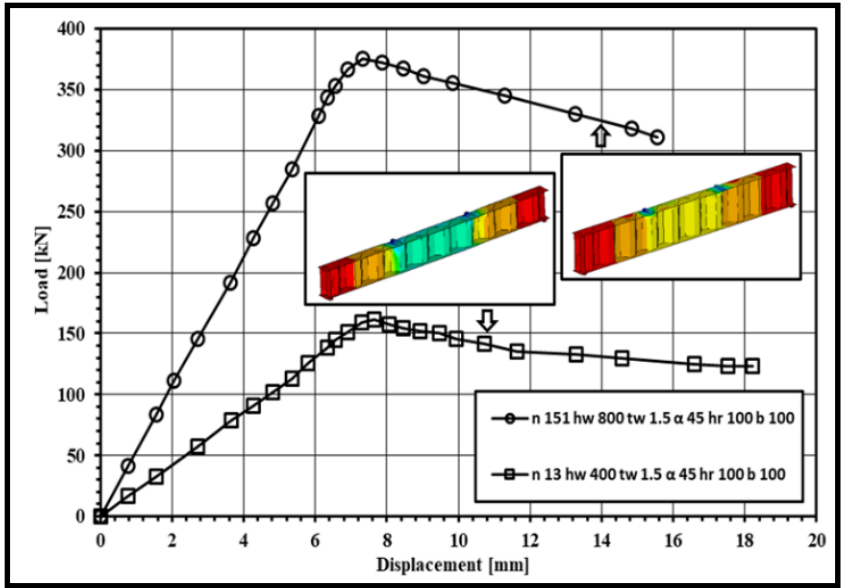

Figure 11: Comparison between the web height 400 and $800 \mathrm{~mm}$ for model number 13 and 151, respectively.

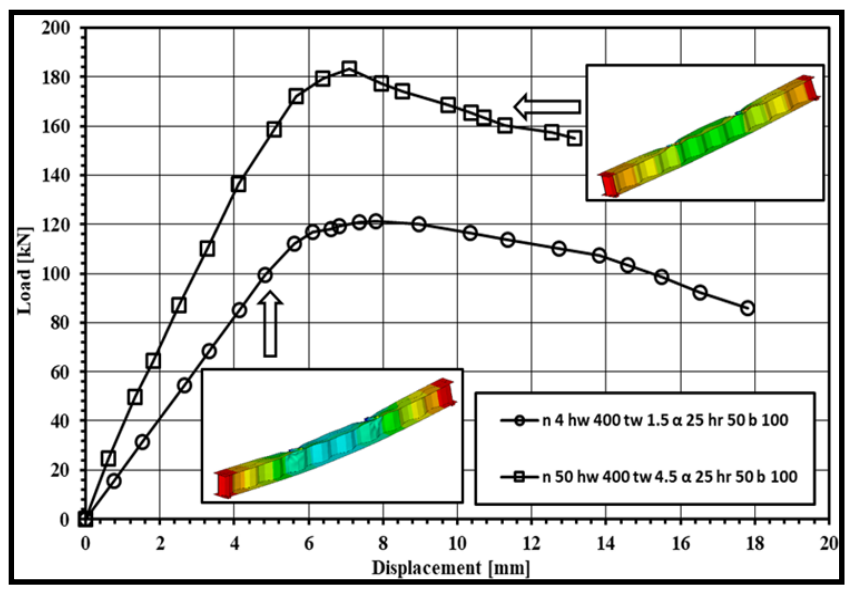

Figure 12: Comparison between the web thickness 1.5 and $4.5 \mathrm{~mm}$ for model number 4 and 50, respectively.

Depending on the angle of corrugation, the thickness of web, the height of web, corrugation depth and flat panel width the failure modes can be different. Figure 9 shows the failure mode for the flat web [n1 hw400 tw1.5 $\alpha 0 \mathrm{hr} 0 \mathrm{~b} 0$ ], the failure mode of the girder was lateral torsion buckling and shear buckling in web and by increasing the angle of corrugation [n10 hw400 tw1.5 $\alpha 45 \mathrm{hr} 50 \mathrm{~b} 100$ ], the failure mode changed to the local buckling in web as shown in Figure 9.

Figure 10 shows the failure mode for the model [n 4 hw400 tw1.5 a $25 \mathrm{hr50}$ b100], where the failure mode is the local buckling in web and the local buckling in flange. Also Figure 10 shows the failure mode for the model [n7 hw400 tw1.5 a25 hr100 b100], where the failure mode was also local buckling in the flange and the web but here the local buckling became larger.

Figure 11 shows the failure mode for the model [n13 hw400 tw1.5 $\alpha 45 \mathrm{hr} 100 \mathrm{~b} 100]$ and the model [n151 hw800 tw1.5 $\alpha 45 \mathrm{hr} 100 \mathrm{~b} 100]$. This failure mode was local buckling in web and by increasing the height of the web from 400 to $800 \mathrm{~mm}$, the buckled zone became smaller.

Finally, by increasing the thickness of web, the failure mode changed from local buckling in flange and web to local buckling in flange only, where local buckling in web becomes very small. Figure 12 shows the failure mode for the model [n4 hw400 tw1.5 $\alpha 25$ hr50 b100], where the failure mode is the local buckling in flange and the local buckling in web. Also Figure 12 shows the failure mode for the model [n50 hw400 tw4.5 $\alpha 25$ hr50 b100], where the failure mode is the local buckling in flange and the local buckling in web became very small.

\subsubsection{Effect of Studied Parameters}

Different parameters can affect the actual behavior of the SGCW such as web thickness, angle of corrugation, height of steel girder, corrugation depth and width of horizontal plate. In all of the following models the length of steel girders remain unchanged [4000 $\mathrm{mm}$ ].

\subsubsection{Effect of the Web Thickness}

To study the effect of the web thickness on the corrugated girders, the three girders with the web thickness tw $=1.5 \mathrm{~mm}$, $3 \mathrm{~mm}$ and $4.5 \mathrm{~mm}$ are taken into account while keeping all other variables constant. It is observed that in the Figures from 13 to 18 when the web thickness increases, the ultimate load increases. In Figure $13\left[\mathrm{hw}=400 \mathrm{~mm}, \alpha=25^{\circ}\right]$ the ultimate load of girder increased by $14.31 \%$ when the thickness of web was increased from 1.5 to $3 \mathrm{~mm}$ while in case the thickness was increased from 3 to $4.5 \mathrm{~mm}$ the ultimate load was increased by $19.65 \%$, in Figure 13 $\left[\mathrm{hw}=600 \mathrm{~mm}, \alpha=25^{\circ}\right]$ the ultimate load of girder increased by $8.37 \%$ when the thickness of web was increased from 1.5 to $3 \mathrm{~mm}$ while in the case of the thickness was increased from 3 to $4.5 \mathrm{~mm}$ the ultimate load was increased by $7.08 \%$ and also in Figure $13\left[\mathrm{hw}=800 \mathrm{~mm}, \alpha=25^{\circ}\right]$ the ultimate load of girder increased by $3.53 \%$ when the thickness of web was increased from 1.5 to $3 \mathrm{~mm}$ while in case the thickness was increased from 3 to $4.5 \mathrm{~mm}$ the ultimate load was increased by $9.32 \%$.

\subsubsection{Effect of the Angle of Corrugation}

To study the effect of the angle of corrugation on the corrugated girders, the five girders with the angle of corrugation $\alpha=0^{\circ}, 25^{\circ}, 45^{\circ}, 65^{\circ}$ and $90^{\circ}$ are taken into account while keeping all other variables constant. It is observed that in the Figures from 13 to 18 when the corrugation angle increases, the ultimate load increases. In Figure $18[\mathrm{hw}=800 \mathrm{~mm}, \mathrm{tw}=1.5 \mathrm{~mm}]$ when the angle was increased from $0^{\circ}$ to $25^{\circ}$, the ultimate load of the girder increased by $36.77 \%$, while if the angle was increased from $25^{\circ}$ to $45^{\circ}$, the ultimate load of the girder increased by $24.49 \%$, while if the angle was increased from $45^{\circ}$ to $65^{\circ}$, the ultimate load of the girder was increased by $8.44 \%$ and when the angle was increased from $65^{\circ}$ to $90^{\circ}$, the ultimate load of the girder increased by $25.60 \%$.

\subsubsection{Effect of the Corrugation Depth}

To study the effect of the corrugation depth on the corrugated girders, the two girders with the corrugation depth $\mathrm{hr}=50 \mathrm{~mm}$ and $100 \mathrm{~mm}$ are taken into account with constant other dimensions. It is observed that in the Figures 
from 13 to 18 when the corrugation depth decreases, the ultimate load increases. In Figure 14 and Figure 17 [hw = $800 \mathrm{~mm}$, tw $=4.5 \mathrm{~mm}, \alpha=25^{\circ}$ ] the ultimate load of girder increased by $18.10 \%$ when the corrugation depth was decreased from 100 to $50 \mathrm{~mm}$, but in the case of angle $45^{\circ}$, $65^{\circ}$ and $90^{\circ}$ the ultimate load of girder increased by $5.56 \%$, $9.83 \%$ and $20.38 \%$ respectively.

\subsubsection{Effect of the Flat Panel Width}

To study the effect of the flat panel width on the corrugated girders, the three girders with the flat panel width $b=0,50$ $\mathrm{mm}$ and $100 \mathrm{~mm}$ are taken into account with constant other dimensions. From Figures 13 to 18 it is observed the inverse relationship between the ultimate load of the girder and the flat panel width whereas the decreasing of flat panel width leads to increasing in the ultimate load of girder. In Figs. 16 to 18 , [hw $=800 \mathrm{~mm}, \mathrm{tw}=4.5 \mathrm{~mm}, \alpha=65^{\circ}$ ] the ultimate load of girder increased by $15.79 \%$ when the flat panel width was decreased from 100 to $50 \mathrm{~mm}$ while in case the flat panel width was decreased from $50 \mathrm{~mm}$ to 0 the ultimate load was increased by $25.12 \%$.

\subsubsection{Effect of the Height of Steel Girder}

To study the effect of the height of steel girder on the corrugated girders, the three girders with the height of steel girder $\mathrm{hw}=400 \mathrm{~mm}, 600 \mathrm{~mm}$ and $800 \mathrm{~mm}$ are taken into account with constant other dimensions. It is observed in Figures 13 to 18 that when the height of steel girder increases, the ultimate load increases as shown in Figure 15 $\left[\mathrm{tw}=1.5 \mathrm{~mm}, \alpha=90^{\circ}\right]$ the ultimate load of girder increased by $31.94 \%$ when the height of steel girder was increased from 400 to $600 \mathrm{~mm}$, but in the case of the height was increased from 600 to $800 \mathrm{~mm}$ the ultimate load was increased by $36.41 \%$. Using thickness $3 \mathrm{~mm}$ the ultimate load of girder increased by $28.53 \%$ when the height of steel girder was increased from 400 to $600 \mathrm{~mm}$, but in the case of the height was increased from 600 to $800 \mathrm{~mm}$ the ultimate load was increased by $39.77 \%$. Finally in the case of the thickness $4.5 \mathrm{~mm}$ and the height of steel girder $600 \mathrm{~mm}$ and $800 \mathrm{~mm}$, the ultimate load of girder was increased by $29.98 \%$ and $31.63 \%$ respectively.

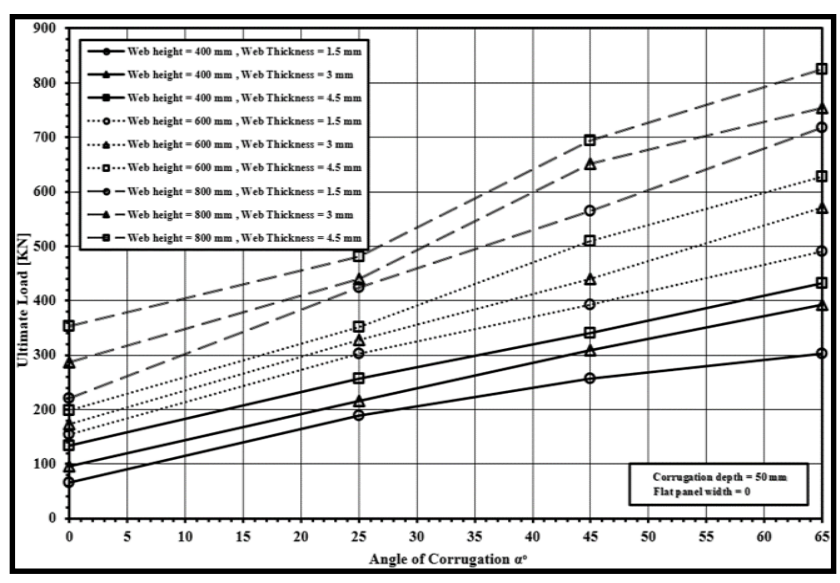

Figure 13: Ultimate load variation with different factors $[\mathrm{hr}=50 \mathrm{~mm}, \mathrm{~b}=\mathbf{0}]$.

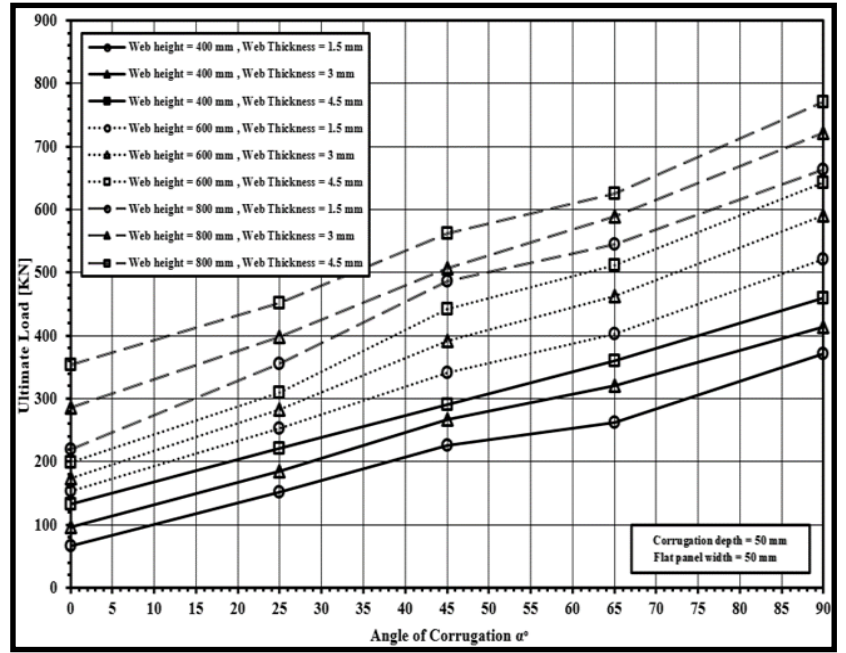

Figure 14: Ultimate load variation with different factors $[\mathrm{hr}=\mathbf{5 0} \mathbf{~ m m}, \mathrm{b}=\mathbf{5 0} \mathrm{mm}]$.

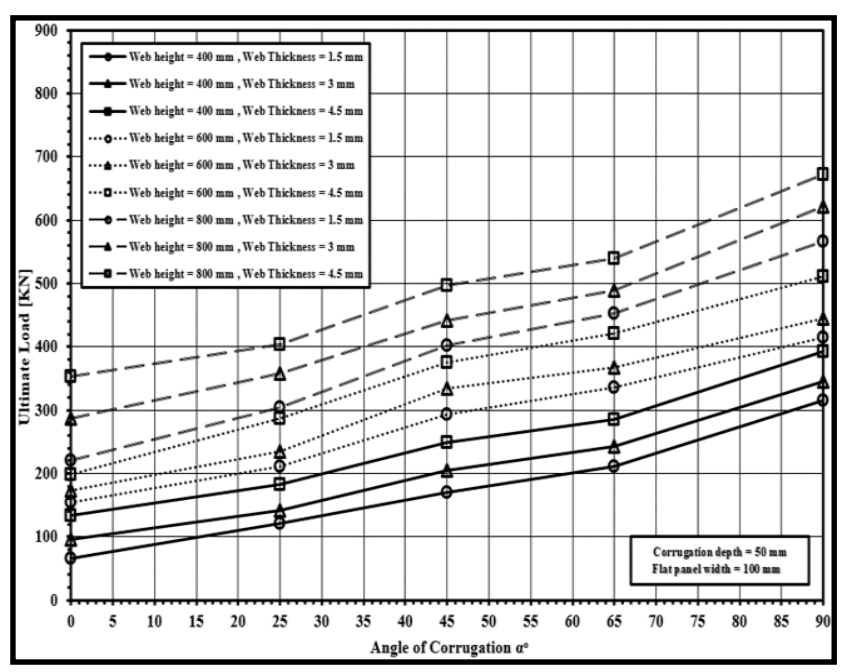

Figure 15: Ultimate load variation with different factors $[\mathrm{hr}=50 \mathrm{~mm}, \mathrm{~b}=\mathbf{1 0 0} \mathrm{mm}]$.

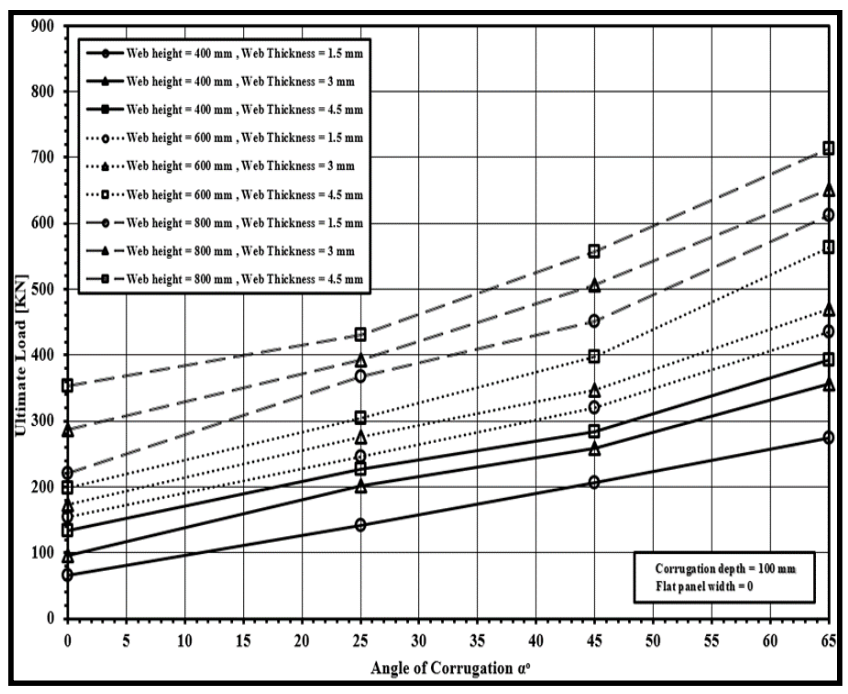

Figure 16: Ultimate load variation with different factors $[\mathrm{hr}=100 \mathrm{~mm}, \mathrm{~b}=\mathbf{0}]$. 


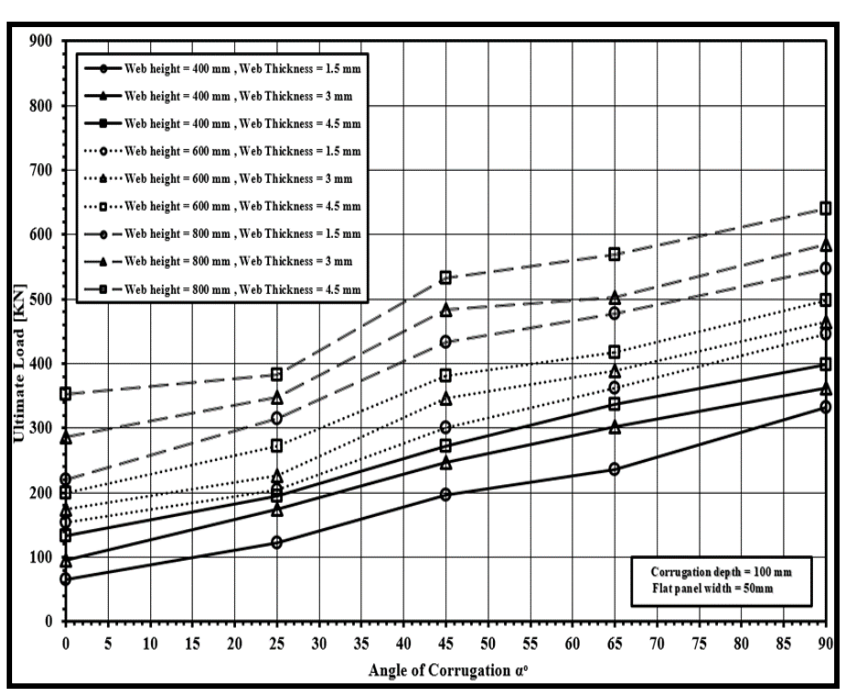

Figure 17: Ultimate load variation with different factors [hr =100 $\mathbf{m m}, \mathrm{b}=\mathbf{5 0} \mathrm{mm}]$.

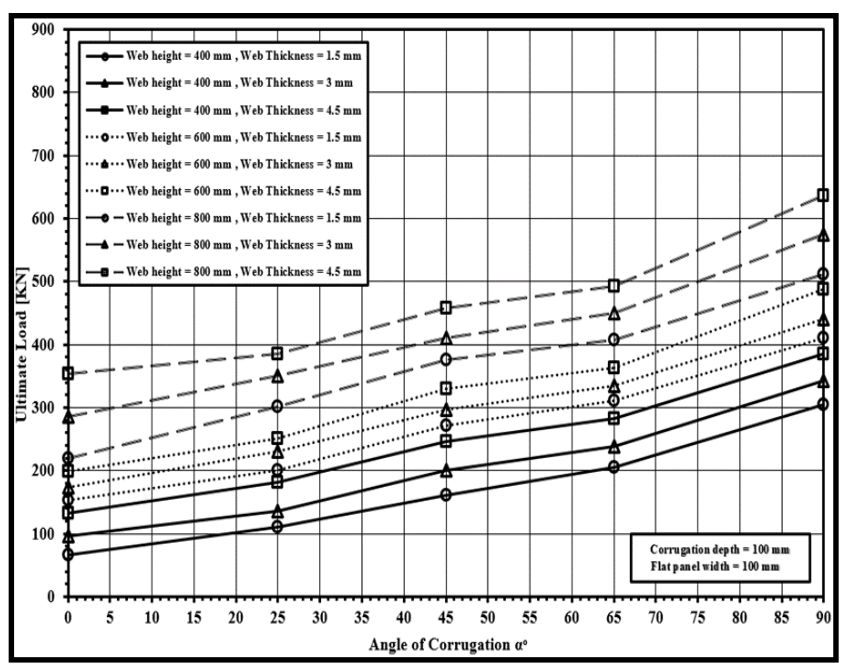

Figure 18: Ultimate load variation with different factors $[\mathrm{hr}=100 \mathrm{~mm}, \mathrm{~b}=100 \mathrm{~mm}]$.

\section{SUMMARY AND CONCLUSION}

This research focuses on the behavior of SGCW subjected to various types of loads using FEM. The verification study was conducted using ANSYS for two different experimental tests on the form of load-displacement curves and the observed failure modes. The verification showed good agreement between the experimental and FEM results for load-displacement behavior and the failure modes. A total of 207 full 3D FE models were created to study the behavior of SGCW subjected to various types of loads with different parameters. Examining the FEA results in the parametric study, it is observed that:-

1. The FEA can simulate the behavior of the SGCW with a very good agreement. It saves time, costs and gives accurate results when compared to the experimental results.
2. The FEA results showed a good agreement with the experimental ones with a difference varies from $4 \%$ to $6 \%$.

3. The parametric study showed that the steel girder with corrugated web can carry high loads when compared to the flat web girder with the following details:

- When the angle of the corrugation increased from $0^{\circ}$ to $25^{\circ}$, the ultimate load of the SGCW increased from $8.19 \%$ to $184.49 \%$.

- When the angle of the corrugation increased from $25^{\circ}$ to $\leqslant 5^{\circ}$, the ultimate load of the SGCW increased from $17.33 \%$ to $61.46 \%$.

- While the angle of the corrugation increased from $45^{\circ}$ to $65^{\circ}$, the ultimate load of the SGCW increased from $3.90 \%$ to $41.61 \%$.

- Finally, when the angle of the corrugation increased from $65^{\circ}$ to $90^{\circ}$, the ultimate load of the SGCW increased from $12.34 \%$ to $49.35 \%$.

4. It is observed that the angle of corrugation of $90^{\circ}$ gives the highest ultimate load.

5. Corrugated web thicknesses, corrugation depth, web height and flat panel width influence the behavior and ultimate load of the steel girder with the following details:

- When the web thickness increased from 1.5 to $4.5 \mathrm{~mm}$, the ultimate load of the SGCW increased from $3.53 \%$ to $45.01 \%$.

- Increasing the height of the web from 400 to $800 \mathrm{~mm}$, the ultimate load of the SGCW increased from $19.72 \%$ to $131.81 \%$.

- While the corrugation depth increased, the ultimate load of the SGCW decreased from $1.21 \%$ to $32.90 \%$.

- Finally, the ultimate load of the SGCW decreased from $1.68 \%$ to $34.92 \%$, when the flat panel width increased.

\section{CREDit Authorship ConTribution STATEMENT:}

Mohamed ELGhandour: Supervision, Visualization, Methodology, Investigation, Reviewing, Editing and Original draft preparation.; Ashraf

Elsabbagh: Supervision, Visualization, Methodology, Literature review, Reviewing, Investigation, Editing, Software, Formal analysis and Original draft preparation.; Tarek Sharaf: Supervision, Visualization, Methodology, Literature review, Reviewing, Investigation, Editing, Software, Formal analysis and Original draft preparation.

\section{DECLARATION OF COMPETING INTEREST:}

We declare that we do not have known competing financial interests or personal relationships that could have appeared to influence the work reported in this paper.

\section{REFERENCES}

[1] ANSYS ${ }^{\circledR}$ program User's Manual, Canonsburg, Pennsylvania, USA.

[2] Heungbae Gil، Seungrok Lee، Jongwon Lee and Hakeun Lee, "Shear Buckling Strength of Trapezoidally Corrugated Steel Webs for Bridge" Journal of the Transportation Research Board CD 11-S, 2005, pp. 473-480. 
[3] V.C. Prabha and K. Selvakumar, "Study on Behavior of Cold Formed Built up I Section with Trapezoidal Corrugation in Web by Varying the Aspect Ratio and Angle of Corrugation", International Journal of Chem. Sci, Vol. 13[4], 2015, pp. 1935-1946.

[4] M. Elgaaly and A. Seshadri, "Girders with Corrugated Webs under Partial Compressive Edge Loading”, Journal of Structural Engineering, Vol. 123, No. 6, 1997, pp.783-791.

[5] B. Kovesdi, L. Dunai and U. Kuhlmann, " Patch loading resistance of girders with corrugated webs", Journal of Constructional Steel Research [66], 2010, 1445-1454.

[6] X. Wang, "Behavior of Steel Member with Trapezoidally Corrugated Web and Tubular Flanges under Static Loading", Doctor of Philosophy Thesis, Drexel University, Philadelphia, United States of America. 2003.

[7] F.M. El-Amin, M.F. Abdel-Khalek, M.M. Ahmed and S.R. Gad, "Nonlinear Behavior of Cantilever Girders with Corrugated Steel Webs" Journal of Engineering Sciences, Assiut University, Vol. 36, No. 6, 2008, pp.1319 - 1338 November.

[8] Q. Cao, H. Jiang and H. Wang, "Shear Behavior of Corrugated Steel Webs in H Shape Bridge Girders" Journal of mathematical problems in engineering, Volume 2015, Article ID 796786, 2015, 15 pages.

[9] Y.A. Khalid, C.L. Chan, B.B. Sahari and A.M.S. Hamouda, "Bending behaviour of corrugated web beams" Journal of Materials Processing Technology, Vol. 150, 2004, pp. 242-254.

[10] R. Divahar and P. S. Joanna, "The Effect of Web Corrugation in Cold-Formed Steel Beam with Trapezoidally Corrugated Web" American Journal of Engineering Research [AJER], Volume. 3, Issue. 6, 2014, pp. 137-142.

[11] F. Denan, M. H. Osman and S. Saad, "The Study of Lateral Torsional Buckling Behaviour of Beam with Trapezoid Web Steel Section by Experimental and Finite Element Analysis" Universiti Sains Malaysia [USM] Nibong Tebal, Penang, Malaysia, Volume. 2, No. 3, 2010, PP. 232240.

[12] G. Arunkumar, P. Sampathkumar and S. Sukumar, "Investigation on Cold Formed Steel Lipped I Beam with Trapezoidal Corrugation in Web by Varying Depth" International Journal of Innovative Research and Development, Volume 2, Issue 5, 2013, pp. 938-950.

[13] L. Krishnan, C.S. Dineshraj and S. Prema, "Experimental Investigation of Cold Formed Steel Section Flexural Member with Triangular Web" Journal of Mechanical and Civil Engineering, Volume 12, Issue 2, 2015, PP. 36-39.

[14] R. Luo and B. Edlund, "Buckling Analysis of Trapezoidally Corrugated Panels Using Spline Finite Strip Method", thin walled structures, vol. 18, 1993, pp. 209-224. [15] R. Luo and B. Edlund, "Ultimate Strength of Girders with Trapezoidally Corrugated Webs Under Patch Loading", Thin-Walled Structures, Vol. 24, 1994, pp.135-156.

[16] A. A. Limaye and P. M. Alandkar, "Strength of Welded Plate Girder with Corrugated Web Plate" Journal of Engineering Research and Applications, Vol. 3, Issue 5, 2013, PP. 1925-1930.
[17] Z. Wen and W. Wei, "Nonlinear Shear Buckling Parametric Finite-Element Analysis of Corrugated Steel Webs" Canadian Center of Science and Education, Vol. 8, No. 4, 2014, PP. 223-229.

[18] K. Aggarwal, S. Wu and J. Papangelis, "Finite element analysis of local shear buckling in corrugated web beams", Engineering Structures, Vol. 162, 2018, pp.37-50.

[19] N. D. Nguyen, S. N. Kim, S. R. Han and Y. J. Kang, "Elastic Lateral Torsional Buckling Strength of I Girder With Trapezoidal Web Corrugations Using a new Warping Constant Under Uniform Moment" Engineering Structures, Vol. 32, 2010, PP. 2157- 2165.

[20] J. Lindner, "Lateral Torsional Buckling of Beams with Trapezoidally Corrugated Webs" Stab Steel Struct Budapest, Hungary, 1990, PP. 305-310.

[21] J. Moon, J. W. Yi, B. H. Choi and H. E. Lee, "Lateral Torsional Buckling of I Girder with Corrugate,2009.

[22] D Webs Under Uniform Bending" Thin Walled Struct, Vol.47, PP.21-30. 